El fideicomiso de inversión forestal como garantía de cierre de minas

Juan Pablo Macassi Zavala

En el presente artículo, el Dr. Macassi analiza los obstáculos de los titulares mineros en nuestro país y la regulación aplicable al cierre de minas, concluyendo cuales deberían ser las garantías más favorables para su cierre de acuerdo al entorno económico actual y las expectativas del mercado minero. Abogados. 


\section{El fideicomiso de inversión forestal como garantía de cierre de minas}

\section{Introducción}

El sector minero es el principal aportante de ingresos a la economía del Perú. Las ventajas que trae consigo se reflejan en el desarrollo social y económico de las regiones en donde existe actividad minera formal, mediante un significativo incremento de los ingresos de las entidades estatales que, bien administrados, permiten el desarrollo de proyectos de interés público en sectores sensibles para la mejora de la calidad de vida de la población (como lo son el sector salud, educación, saneamiento y transporte).

No obstante, innegablemente la actividad minera transforma la naturaleza y tiene un impacto en el ambiente y la población dentro de su área de influencia. Este impacto ocurre desde la etapa de exploración minera, y se intensifica durante la etapa de construcción (desarrollo) de los emprendimientos mineros que llegarán a la etapa de explotación del mineral. Casi la totalidad de estos impactos, una vez generados, tienden a permanecer en el tiempo si no existen acciones para eliminarlos, mitigarlos 0 controlarlos. Este es el caso de los pasivos ambientales de la industria minera que se encuentran a lo largo del territorio peruano de los cuales el Ministerio de Energía y Minas realiza un inventario que actualiza periódicamente, ${ }^{1}$ y de los que, en su gran mayoría, no se ha identificado al responsable obligado a manejar sus impactos.

Los pasivos ambientales son la consecuencia de que en el Perú se haya desarrollado, por largo tiempo y hasta hace poco más de veinte años, una industria minera sin que exista una regulación de protección ambiental que establezca claramente las responsabilidades por las instalaciones luego de que las actividades mineras culminen. Se debe tener bajo consideración que un emprendimiento minero culminará en un tiempo determinado, es una consigna que surge del solo hecho de saber que el objeto de la industria es el aprovechamiento de un recurso natural no renovable.

De esa forma, en el Perú ahora se evidencian las consecuencias de que en el pasado no existieran reglas que internalicen los costos a los titulares mineros, tanto por el manejo de sus desechos durante las operaciones mineras, como por el manejo de sus instalaciones una vez que se terminaba la explotación del yacimiento minero. Esta situación, felizmente ya superada, ejemplifica lo que Garret Hardin denominó como la tragedia de los bienes comunes. ${ }^{2}$

1 La última actualización fue realizada mediante la Resolución Ministerial 102-2015MEM/DM, publicada el 09 de marzo de 2015.

2 Chase Smith, Richard y Pinedo, Danny, El cuidado de los bienes comunes: gobierno y manejo de los lagos y bosques en la Amazonía, Primera Edición, IEP, Instituto del Bien Común, 2002, p. 33. 
Atendiendo a ese escenario es que en el año 1993, mediante el Reglamento para la Protección Ambiental en la Actividad Minera - Metalúrgica ${ }^{3}$, se crea por primera vez en el Perú la figura del Plan de Cierre de Minas, como uno de los instrumentos de gestión ambiental aplicables a la actividad minera. En esta misma regulación se prevé la necesidad de contar con un Estudio de Impacto Ambiental para las nuevas operaciones, o con un Programa de Adecuación y Manejo Ambiental (PAMA) para aquellas unidades que se encontraban en operación al momento de la entrada en vigencia de la norma. Es decir, este reglamento instauró los instrumentos de gestión ambiental aplicables a la actividad minera.

Aunque sin duda alguna el Reglamento para la Protección Ambiental en la Actividad Minera - Metalúrgica constituye un hito en la legislación ambiental sectorial, en lo referido al cierre de minas, el Estado consideró la necesidad de establecer reglas específicas en normas distintas al mencionado reglamento, debido a la problemática existente por el abandono de operaciones mineras, que era una práctica común en la industria minera. Esto se evidencia en la Exposición de Motivos del Proyecto de Ley 4764/2002-CR que originó la actual la Ley que Regula el Cierre de Minas, Ley 28090, del año 2003:

"Las prácticas de cierre de minas existentes en el Perú, por lo general incluyen el abandono de la mina o el componente de la mina, sin una asignación mínima de recursos para la estabilización, recuperación o manejo de agua superficial. Además numerosas operaciones mineras han sido abandonadas sin ninguna consideración por las implicancias ambientales en el corto, mediano o largo plazo. No se efectúa una planificación permanente del cierre de minas, para evitar el drenaje ácido de roca, la lixiviación de sustancias contaminantes hacia el agua superficial o el agua subterránea, o que partículas esparcidas por el viento, impacten sobre la calidad del aire. Tampoco se tienen en cuenta los casos extremos de sismos, precipitaciones o deslizamientos.

Un adecuado cierre de minas, considera el desarrollo de estructuras que permanezcan siempre seguras y estables, así como la protección ambiental de los recursos de agua y del aire, lo que requiere de planificación y gastos durante la operación aun después de concluida la actividad minera." ${ }^{4}$

Adicionalmente, la ejecución del Plan de Cierre de Minas no estaba asegurada correctamente mediante un sistema de garantías desde el inicio de la ejecución del proyecto, lo cual generaba un riesgo para el Estado de que mediante mecanismos legales los titulares mineros llegaran a evadir su responsabilidad respecto al cierre de sus instalaciones. Esta situación se grafica también en la Exposición de Motivos del Proyecto de Ley 4353/2002-CR, uno de los antecedentes de nuestra ley actual de cierre de minas:

3 Aprobada mediante el Decreto Supremo 016-93-EM.

$4 \quad$ Proyecto de Ley 4764/2002-CR. p. 11. 
“Del análisis de nuestra legislación es de verse que las labores de rehabilitación, refacción y restauración, así como las acciones orientadas a recuperar la tierra afectada por la minería, de tal manera que sea regresada en condiciones favorables para las personas y el medio ambiente, se contemplan al final de las operaciones mineras en el denominado Plan de Cierre, cuando las compañías podrían dirigirse a declararse en bancarrota, como ha sucedido muchas veces en el pasado, transfiriendo la obligación económica de estos pasivos ambientales al gobierno". 5

De esta forma, la legislación para la protección ambiental durante la etapa de cierre de minas continuó evolucionando y se aprobó la mencionada Ley 28090, Ley que regula el Cierre de Minas y posteriormente, su Reglamento aprobado mediante Decreto Supremo 033-2005-EM. Estas normas sustituyeron, en lo referido al cierre de minas, lo establecido en el Reglamento para la Protección Ambiental en la Actividad Minera Metalúrgica. ${ }^{6}$

\section{Regulación aplicable al cierre de minas}

\subsection{Caso de Perú}

En el Perú, la Ley General del Ambiente, Ley 28611, en su artículo $27^{7}$, señala que los titulares de todas las actividades económicas deben garantizar que al cierre de actividades 0 instalaciones no subsistan impactos ambientales negativos de carácter significativo, debiéndose considerar tal aspecto al diseñar y aplicar los instrumentos de gestión ambiental ${ }^{8}$ que les corresponda de conformidad con el marco legal vigente.

$5 \quad$ Proyecto de Ley 4353/2002-CR. p. 7.

6 Debe notarse que el Reglamento para la Protección Ambiental en la Actividad Minera Metalúrgica quedará derogado con la entrada en vigencia del Reglamento de Protección y Gestión Ambiental para las Actividades de Explotación, Beneficio, Labor General, Transporte y Almacenamiento Minero, aprobado por el Decreto Supremo 040-2014-EM. Esta norma, en su artículo 37, también refiere a la Ley que Regula el Cierre de Minas y su Reglamento en lo que respecta al Plan de Cierre de Minas, razón por la cual no afecta la vigencia o eficacia de dichas normas.

$7 \quad$ Artículo 27.- De los planes de cierre de actividades

Los titulares de todas las actividades económicas deben garantizar que al cierre de actividades 0 instalaciones no subsistan impactos ambientales negativos de carácter significativo, debiendo considerar tal aspecto al diseñar y aplicar los instrumentos de gestión ambiental que les correspondan de conformidad con el marco legal vigente. La Autoridad Ambiental Nacional, en coordinación con las autoridades ambientales sectoriales, establece disposiciones específicas sobre el cierre, abandono, post-cierre y post-abandono de actividades o instalaciones, incluyendo el contenido de los respectivos planes y las condiciones que garanticen su adecuada aplicación.

$8 \quad$ La Ley General del Ambiente define a los instrumentos de gestión ambiental como los medios operativos diseñados, normados y aplicados para efectivizar el cumplimiento de la Política Nacional Ambiental y las normas ambientales del país, incluyendo aquellos 
Este mismo postulado se encuentra en la legislación sectorial minera, en el que la Ley que Regula el Cierre de Minas (anterior a la Ley General del Ambiente) prevé el instrumento para el cierre de minas de dos maneras, no excluyentes entre sí: i) el Plan de Cierre Conceptual, que forma parte del Estudio Ambiental correspondiente, según la categoría del proyecto minero; y, ii) el Plan de Cierre de Minas, previsto como un instrumento de gestión ambiental independiente y obligatorio en determinados escenarios.

\subsubsection{Plan de Cierre Conceptual}

Este Plan de Cierre de Minas forma parte del Estudio Ambiental que se requiere para el desarrollo de las actividades mineras, integrando dicho instrumento como uno de sus capítulos. De esta forma, en todo estudio ambiental necesario para realizar actividades mineras, se debe incluir el Plan de Cierre Conceptual, el cual debe identificar y describir las medidas estimadas para el cierre de las labores y el desmantelamiento de los diversos componentes del proyecto o unidad minera, incluyendo las actividades de monitoreo posteriores al cierre que resulten necesarias (etapa de post cierre).

En los casos de las actividades de exploración minera, el Plan de Cierre Conceptual se incluye en la Declaración de Impacto Ambiental (ya sea de aprobación automática o evaluación previa) o en el Estudio de Impacto Ambiental Semidetallado, según la magnitud del proyecto de exploración de acuerdo a la clasificación establecida en el Reglamento Ambiental para las Actividades de Exploración Minera. ${ }^{9}$ En los casos de las actividades de explotación y procesamiento minero, el Plan de Cierre Conceptual debe incluirse en el Estudio de Impacto Ambiental o en el Estudio de Impacto Ambiental Semidetallado, también de acuerdo a su clasificación atendiendo a la intensidad de los impactos que se identifiquen ${ }^{10}$.

En este sentido, el Plan de Cierre Conceptual ocurre con la aprobación del respectivo Estudio Ambiental, que a su vez constituye la Certificación Ambiental del proyecto minero. La aprobación del Plan de Cierre Conceptual obliga al titular minero a ejecutar las medidas de cierre y post cierre previstas, sin embargo, no genera la obligación de presentar un Plan de Cierre de Minas o constituir garantías para su cumplimiento.

\subsubsection{Plan de Cierre de Minas}

destinados a la evaluación del impacto ambiental y el cumplimiento de las obligaciones de cierre.

$9 \quad$ Aprobado mediante el Decreto Supremo 020-2008-EM.

10 De acuerdo al reciente Reglamento de Protección y Gestión Ambiental para las Actividades de Explotación, Beneficio, Labor General, Transporte y Almacenamiento Minero, aprobado por el Decreto Supremo 040-2014-EM. 
El Plan de Cierre de Minas es definido como un instrumento de gestión ambiental conformado por acciones técnicas y legales efectuadas por los titulares mineros, destinado a establecer medidas que se deben adoptar para rehabilitar el área utilizada o perturbada por la actividad minera, a fin de compatibilizar el ecosistema para hacerlo saludable, adecuado para el desarrollo de la vida y la preservación paisajista. Dicha rehabilitación debe realizarse ejecutando las medidas previstas antes, durante y después del cierre de las operaciones de la unidad minera, incluyendo también las actividades de post cierre.

Este instrumento debe ser presentado por los titulares mineros en el plazo máximo de un año a partir de la aprobación del Estudio de Impacto Ambiental y es una obligación exigible a todo titular de la actividad minera que se encuentre en operación (explotación), ya sea en la fase de desarrollo minero (construcción de la mina) o de producción. En este sentido, los sujetos obligados para cumplir esta obligación son aquellos que pretendan realizar actividades de explotación minera, ya sea como inicio de las mismas, o como reinicio después de haberlas suspendido o paralizado antes de la vigencia de la Ley que Regula el Cierre de Minas.

No obstante lo anterior, esta regulación resulta también aplicable a los titulares de las actividades de exploración minera que realicen exploración con labores subterráneas que impliquen la remoción de más de diez mil toneladas de material o más de mil toneladas de material con una relación de potencial de neutralización (PN) sobre potencial de acidez (PA) menor a tres (PN/PA< 3), en muestras representativas del material removido. Sin embargo, la regulación establece que, en estos casos, el Plan de Cierre se presenta como anexo de la Evaluación Ambiental o de la modificación correspondiente que implique la remoción total de dicho volumen de material y se aprueba conforme al procedimiento de la evaluación ambiental aplicable a las actividades de exploración minera. En tal sentido, no se genera la obligación para los titulares de exploración minera de obtener una aprobación específica de su Plan de Cierre de Minas (como lo es para los actividades de explotación minera), sin embargo, como veremos más adelante, que se les incluya en esta regulación los obliga a tener que constituir las garantías para el cierre de minas de forma similar a los titulares que se encuentran en la etapa de desarrollo o explotación minera.

Por otro lado, cabe señalar que las obligaciones y responsabilidades del titular minero contraídas por el Plan de Cierre de Minas no cesan por la extinción de la concesión minera. Del mismo modo, aun cuando las áreas e instalaciones se encuentren en posesión de un tercero, todo titular minero es responsable del cierre de dichas áreas, labores e instalaciones, para lo cual podrá solicitar la imposición de las servidumbres que resulten necesarias.

En caso se haya producido la cesión o transferencia de la unidad minera, el cesionario o adquiriente tendrá la obligación de ejecutar el Plan de Cierre de Minas aprobado, 
debiendo constituir la garantía remplazando o complementando la otorgada por el transferente o cedente.

En los casos de la gran y mediana minería, la autoridad competente para aprobar el Plan de Cierre de Minas y sus respectivas modificaciones es la Dirección General de Asuntos Ambientales Mineros del Ministerio de Energía y Minas. Según las características del proyecto minero, esta autoridad solicitará opinión a diferentes entidades que ejerzan funciones relacionadas al cierre de minas propuesto, como la Autoridad Nacional del Agua o el Servicio Nacional de Áreas Naturales Protegidas. Por otro lado, la Dirección General de Minería del Ministerio de Energía y Minas es la autoridad competente para evaluar los elementos económicos y financieros del Plan de Cierre de Minas, y es el Organismo de Evaluación y Fiscalización Ambiental (OEFA) la autoridad competente para fiscalizar el cumplimiento de dicho plan.

Finalmente, debe resaltarse que, con la aprobación del Plan de Cierre de Minas, surge la obligación de constituir la garantía de su cumplimiento, en el monto y forma que se haya establecido en el mismo. Detallaré este punto más adelante, luego de explicar brevemente la regulación del cierre de minas en países con una tradición minera similar a la peruana.

\subsection{Caso de Argentina}

En Argentina ocurrió un caso parecido al peruano, pues antes de la década de 1990, no existía una regulación destinada a la protección ambiental en las actividades mineras. Los cimientos para esta regulación se dieron con la Ley 24.196, Ley de Inversiones Mineras, y se desarrolló con mayor amplitud en 1995, mediante la Ley 24.585, Ley de Protección Ambiental, que modificó el Código de Minería argentino e incluyó un título complementario destinado a la protección ambiental para la actividad minera.

Este marco legal prevé que en los instrumentos de gestión ambiental de las actividades mineras, que se aprueban mediante una Declaración de Impacto Ambiental, deben incluir las medidas de prevención, mitigación y rehabilitación del impacto negativo de las operaciones mineras.

Sin embargo, a diferencia del Perú, la legislación argentina aún no cuenta con una norma específica que regule la etapa de cierre de minas u ordene la constitución de una garantía para su ejecución.

\subsection{Caso de Chile}

Hasta el año 2011, que se promulgó la Ley 20.551, Ley que Regula el Cierre de Faenas e Instalaciones Mineras, Chile no contaba con una legislación específica para el plan de cierre de minas. Antes de dicho año, el cierre de minas, denominado cierre de faenas mineras, estaba comprendido dentro de las reglas contenidas en el Sistema de Evaluación de Impacto Ambiental previsto en la Ley 19.300. Este plan de cierre se 
insertaba en el Estudio Ambiental de manera descriptiva, sin prever las garantías financieras que sí están reguladas en la ley vigente. Es decir, una situación similar a la peruana antes de la entrada en vigencia de nuestra Ley que Regula el Cierre de Minas del año 2003.

La Ley 20.551, Ley que Regula el Cierre de Faenas e Instalaciones Mineras en Chile, contiene las siguientes innovaciones en su regulación:

- Se deben desarrollar las medidas del plan de cierre de faenas durante la ejecución de las operaciones mineras, el cierre parcial y el cierre final.

- Se deben establecer garantías para asegurar el cumplimiento del plan de cierre de faenas e instalaciones mineras.

- Se establecen sanciones ante el incumplimiento del plan de las medidas aprobadas en el plan de cierre de faenas.

- Para el post cierre, los titulares mineros deberán depositar un monto no reembolsable al Fondo para la Gestión de Faenas Mineras Cerradas. El objetivo de este fondo es asegurar la estabilidad física y química del lugar en que se ha efectuado el plan de cierre.

- La obtención del certificado de cierre final por parte del titular minero, y el correspondiente pago al Fondo, liberan al titular de la responsabilidad por la implementación de las medidas de post cierre.

Si bien esta regulación tiene cierta similitud con la legislación peruana, existe una diferencia sumamente interesante, y es que en Chile la ejecución del Plan de Cierre de Faenas e Instalaciones Mineras solo está previsto a ser ejecutado por el titular minero hasta el cierre final, reservando el post cierre al Fondo de la Gestión de Faenas Mineras Cerradas, para lo cual el titular minero debe realizar el depósito de un monto determinado.

Ello significa que la responsabilidad por el post cierre de las instalaciones se traslada al Estado. Sin embargo, el costo por su ejecución se mantiene a cargo del titular minero, que deberá realizar su pago por adelantado para obtener el certificado de cierre final.

\section{I I. La obligación de garantizar la ejecución del cierre de minas}

La Ley que Regula el Cierre de Minas incorpora la obligación de constituir garantías ambientales financieras como consecuencia de la aprobación del Plan de Cierre de Minas. Esta garantía busca asegurar que el titular minero cumpla con las obligaciones derivadas de dicho plan, o que de lo contrario, el Estado ejecute la garantía para realizar las labores de cierre. La necesidad de esta garantía era posible de anticipar incluso antes de la existencia misma de la ley, tal como señaló Enrique Ferrando en 1999: 
"Los países que han incorporado en sus legislaciones obligaciones relativas al cierre de minas, exigen al titular de la actividad la constitución de garantías que aseguren el cumplimiento de sus obligaciones ambientales después del cierre. Y el Perú no será la excepción a esa regla. El propósito de la garantía es el de permitir al Estado ejecutar el Programa de Cierre con el producto de su ejecución, si el titular de la actividad minera no cumple la obligación o la cumple en forma parcial, tardía o defectuosa."11

Esta obligación evita que los costos por el cierre de los componentes mineros sean trasladados al Estado o a la sociedad en general, ante un eventual incumplimiento del titular minero.

Estas garantías deben cubrir los costos de ejecución de las medidas de rehabilitación para los períodos de operación, de cierre final y post cierre, resultando posible la liberación de las garantías cuando estas medidas hayan concluido a satisfacción del Estado. Las garantías deben ser constituidas por los titulares mineros a partir del año siguiente a la fecha de aprobación o modificación del Plan de Cierre de Minas, dentro de los primeros doce días hábiles de cada año.

Las consecuencias por no constituir la garantía del cierre de minas varían según la etapa en la que se encuentre el emprendimiento minero. Sin embargo, buscan impedir el desarrollo de las actividades mineras hasta que no se constituya dicha garantía de acuerdo al Plan de Cierre de Minas. Así, el titular minero que aún no inicia operaciones estará impedido de realizar actividades de exploración con las labores subterráneas que originaron la necesidad del Plan de Cierre de Minas, o realizar actividades de explotación y procesamiento minero, de ser este el caso.

Tratándose de actividades en operación, la consecuencia prevista por no constituir la garantía de cierre de minas es la paralización de las operaciones hasta por un plazo máximo de dos años. En caso haya vencido este plazo sin haber constituido la garantía ambiental, el titular estará obligado a ejecutar inmediatamente las medidas que se establecen en su Plan de Cierre de Minas aprobado, sin perjuicio de las demás acciones legales aplicables que resulten pertinentes.

Ahora bien, la legislación establece ciertas características que deben cumplir las garantías:

- Ser lo suficientemente líquida o permitir una conversión sencilla de la garantía en dinero.

- $\quad$ Debe contar con documentación legal saneada. 
- $\quad$ No debe recaer en bienes que estén afectos a obligaciones previas, que pudieran disminuir su valor en relación al monto garantizado.

- $\quad$ Su valor será permanentemente actualizado.

- Debe tener el respaldo de una entidad financiera supervisada por la Superintendencia de Banca, Seguros y AFP.

De las características expuestas se desprende que la regulación busca que la garantía sea idónea para que pueda hacerse efectiva ante un eventual incumplimiento de las medidas de cierre del titular minero. Ello se traduce en la búsqueda de garantías de fácil cobro en donde obstáculos como la falta de documentación, la existencia de grados de prelación, o la falta de liquidez, son suprimidos preventivamente a fin que la sociedad no asuma costos que debieron ser asumidos por el titular minero.

Por otro lado, debe notarse que nuestra legislación establece distintas modalidades para garantizar el cierre de minas, dentro de las cuales se encuentran las cartas fianzas u otros mecanismos financieros equivalentes, pólizas de caución y otros seguros, todos ellos emitidos de conformidad con la Ley General del Sistema Financiero y del Sistema de Seguros y Orgánica de la Superintendencia de Banca y Seguros, Ley 26702. Asimismo, es posible constituir fideicomisos en efectivo, sobre administración de flujo, sobre bienes muebles e inmuebles distintos a las concesiones mineras para actividades mineras y a las instalaciones objeto del Plan de Cierre de Minas, o sobre valores negociables excluyendo aquellos emitidos por el titular de la actividad minera. Estas modalidades de garantías pueden ser ampliadas mediante Resolución Ministerial del Ministerio de Energía y Minas.

El titular minero puede presentar una sola garantía que comprenda todas las actividades de cierre, o varias garantías utilizando las distintas modalidades señaladas anteriormente.

\section{El fideicomiso de inversión forestal como garantía del cierre de minas}

En el año 2006, mediante la Ley de Promoción de la Inversión Privada en Reforestación y Agroforestería, Ley 28852, declaró de interés nacional la promoción de la inversión privada en actividades de reforestación con plantaciones forestales, agroforestería y servicios ambientales. Esta norma se emite debido a lo siguiente:

"]...] las áreas deforestadas en el país alcanzan la cifra de 10 millones de hectáreas, las mismas que son extensiones de terreno improductivas que no producen ningún ingreso ni sirven al desarrollo.

[...]

Las plantaciones constituyen una alternativa de suma importancia para optimizar la producción y productividad de agroforestería, forestación y reforestación, recuperar zonas degradadas, dar valor económico a grandes 
extensiones improductivas, generar inversiones privadas, promover transferencia de tecnología y generar empleo en el campo.

Es necesario establecer normas jurídicas que permitan al Estado implementar medidas de promoción de dichas actividades económicas, determinando mecanismos para fomentar la inversión, utilizar fondos de cooperación internacional, e instrumentar mecanismos para captar recursos de conservación de bosques y otros."12

De esta forma, la referida Ley estableció que el Estado promovería el desarrollo de proyectos de reforestación y/o agroforestaría en las áreas de influencia de los proyectos de inversión pública o privada en infraestructura vial, de irrigaciones, energía, minería y otras áreas especiales.

Cumpliendo dicho mandato, el 04 de noviembre de 2006, el Ministerio de Energía y Minas publicó la Resolución Ministerial 515-2006-MEM/DM, que aprobó el Reglamento para evaluar y aceptar el Fideicomiso sobre "Inversión Forestal" en garantía del cumplimiento del Plan de Cierre de Minas. Esta norma permite que los titulares mineros constituyan un patrimonio fideicometido sobre las unidades de negocio que conforman una "Inversión Forestal" sobre tierras de su propiedad o de terceros sin cubierta boscosa, afectándolo a favor del Ministerio de Energía y Minas con la finalidad de que sirva de garantía del cumplimiento del Plan de Cierre de Minas.

De esta forma, el Ministerio de Energía y Minas amplió el espectro de modalidades de garantías que pueden ser utilizadas por los titulares mineros a fin de asegurar el cumplimiento de las medidas de cierre y post cierre de los Planes de Cierre de Minas.Para esos efectos, el referido reglamento definió como "Inversión Forestal" a la actividad que tiene por objeto la instalación, administración, conservación y protección de plantaciones forestales con fines de producción y aprovechamiento de los recursos que se obtengan, y la industrialización de tales recursos forestales, de acuerdo con el principio del uso adecuado y sostenible de los recursos naturales.

Aunque este reglamento establece disposiciones específicas que deben cumplirse para que la autoridad acepte el fideicomiso como garantía del Plan de Cierre de Minas, el mecanismo como tal se rige por la normativa general, razón por la cual se trata de un fideicomiso en garantía que tendrá las siguientes partes:

- $\quad$ Patrimonio fideicometido

El patrimonio fideicometido en un fideicomiso de inversión forestal estará compuesto por todas las unidades de negocio que conformen una "inversión forestal", entendiéndose éste como ha sido definido líneas arriba.

Proyecto de Ley 14668/2005-CR 
En ese orden de ideas, los contratos de derechos superficiales necesarios para la ejecución de la inversión forestal también formarían parte del patrimonio fideicometido, al estar estos activos destinados a la ejecución del proyecto. Asimismo, al señalar la norma que la inversión forestal deberá estar ubicada necesariamente en terrenos sin cubierta boscosa, se denota que el objetivo de este tipo de garantía es que el valor económico del proyecto de inversión forestal se incremente gradualmente en el tiempo, lo cual debería ser evidenciado en las valorizaciones anuales que el titular minero debe presentar a la autoridad.

- $\quad$ Fideicomitente

El fideicomitente deberá ser necesariamente el titular minero en su calidad de obligado al cumplimiento de las obligaciones derivadas de su Plan de Cierre de Minas.

Cabe señalar que existe la posibilidad de que el titular minero se asocie en participación con un tercero cuando la inversión forestal no se realice sobre terrenos de propiedad del titular. En estos casos deben definirse los porcentajes de participación de cada uno y las cláusulas que fueran necesarias para asegurar la continuidad del proyecto de inversión forestal.

Asimismo, el titular minero puede incluir en el contrato de fideicomiso la participación de entidades privadas o públicas dedicadas a la promoción y/o manejo forestal en condición de fideicomitentes.

- $\quad$ Fideicomisario

En los casos de los fideicomisos de inversión forestal, para garantizar el cierre de minas, es el Ministerio de Energía y Minas quien deberá asumir el rol de fideicomisario, siendo el beneficiario del fideicomiso y teniendo carácter de acreedor ante la obligación del titular minero respecto a la ejecución de su Plan de Cierre de Minas.

- $\quad$ Fiduciario

Sobre el particular, la norma del Ministerio de Energía y Minas no establece ninguna disposición específica, razón por la cual, teniendo en consideración la legislación del sistema financiero y fideicomisos, los fiduciarios deberán ser aquellas empresas autorizadas por la Superintendencia de Banca, Seguros y AFP.

Adicionalmente, como parte del desarrollo del proyecto de inversión forestal, se deberá contratar un operador forestal. Esta contratación deberá ser realizada por el fiduciario como parte de sus deberes para cumplir con el objetivo del fideicomiso de inversión forestal. 
Ahora bien, como se ha mencionado, el Reglamento para evaluar y aceptar el Fideicomiso sobre "Inversión Forestal" en garantía del cumplimiento del Plan de Cierre de Minas establece los requisitos específicos que estos tipos de fideicomisos deben cumplir para ser aceptados como garantía del Plan de Cierre de Minas.

Así, se establece que el contrato de fideicomiso debe incluir en sus cláusulas lo siguiente (de forma adicional a lo antes señalado):

Una descripción detallada del proyecto de inversión forestal otorgado en garantía, el área incluida, tipo de recursos, plantaciones previstas y el plan de negocios que se llevará a cabo anualmente por el tiempo que dure la inversión forestal. Este plan comprenderá los aspectos económicos, ambientales y sociales, y el plan de aprovechamiento por el tiempo del mismo.

- Una póliza de seguros contra riesgos que comprendan incendios, desastres naturales, convulsión social u otras causas análogas y sus consecuencias. Dicha póliza será contratada por el titular minero y endosada a favor del Ministerio de Energía y Minas, hasta donde alcancen sus derechos en la inversión forestal.

- Valorización inicial del monto aportado por el titular de actividad minera, el presupuesto previsto, el costo del plan de negocios y los seguros. Sobre este particular se establece también que el titular de actividad minera deberá presentar al Ministerio de Energía y Minas, dentro de los últimos tres meses de cada año calendario, valorizaciones actualizadas de la Inversión Forestal efectuada por empresas auditoras nacionales 0 extranjeras debidamente acreditadas.

- $\quad$ La supervisión del inventario y de la valorización anual por parte del Ministerio de Energía y Minas o las entidades que éste designe.

El proyecto de dicho contrato de fideicomiso deberá ser presentado al Ministerio de Energía y Minas dentro del procedimiento de evaluación del Plan de Cierre de Minas o su modificación, adjuntando la siguiente documentación:

Proyecto de inversión forestal, con detalle del estudio de factibilidad suscrito por ingeniero forestal, áreas previstas, cronograma, plan de negocios que incluya los aspectos económicos, ambientales y sociales del proyecto.

- El proyecto y el estudio de factibilidad con los planos de las zonas de intervención respectivos deben ser suscritos por un ingeniero forestal y el representante legal del titular minero, y la evaluación económica-financiera del proyecto debe ser refrendado por una institución supervisada por la Superintendencia de Banca, Seguros y AFP.

- Documentos que acrediten los derechos de propiedad del titular minero. En los casos en que la inversión forestal se realice sobre tierras de propiedad de terceros, se deberá adjuntar los contratos respectivos que permitan el desarrollo 
de la inversión forestal, los que podrán ser suscritos bajo la modalidad de usufructo, alquiler de tierras, asociación en participación, entre otros.

- Monto previsto del aporte inicial al proyecto, considerando el costo del mismo, financiamiento directo y demás derechos tangibles o intangibles a ser aportados al proyecto.

- $\quad$ Monto de la garantía para los fines del cierre de mina.

- $\quad$ Plazo de liquidación de la Inversión Forestal.

- En los contratos antes referidos deben constar los porcentajes de participación del titular de la actividad minera y de dichos terceros, si fuera el caso, así como otras cláusulas que fueran necesarias para asegurar la continuidad del proyecto de inversión forestal.

El contrato de fideicomiso deberá estar vigente hasta el término de la etapa de post cierre del proyecto o unidad minera, o de lo contrario el titular minero deberá comprometerse a sustituir el contrato de fideicomiso en garantía por otra garantía a satisfacción del Ministerio de Energía y Minas por los importes que resulten necesarios.

Del mismo modo, en caso que la valorización anual de la inversión forestal resulte insuficiente para cubrir el monto anual de la garantía para el cierre de minas, el titular minero deberá cubrir el monto faltante con otra garantía de acuerdo a las modalidades aceptadas por la legislación. Asimismo, en caso esta valorización anual refleje una disminución de su rentabilidad que lo convierta en inviable, la autoridad requerirá que se sustituya la garantía en un plazo máximo de cuarenta y cinco días, con apercibimiento de que se apliquen las reglas sobre incumplimiento de garantías de cierre de minas.

Por otro lado, el Reglamento para evaluar y aceptar el Fideicomiso sobre "Inversión Forestal" en garantía del cumplimiento del Plan de Cierre de Minas establece también limitaciones para la utilización del fideicomiso de inversión forestal como garantía de cierre de minas, e impone condiciones para que los titulares puedan utilizarla.

En primer lugar, el fideicomiso en garantía no puede superar en ningún caso el $50 \%$ del porcentaje máximo de la garantía aprobada (en total, para la vida útil de la mina, como para el monto anual calculado) para el cierre de minas de cada proyecto 0 unidad minera. En tal sentido, necesariamente el titular minero deberá hacer uso de otra u otras modalidades de garantías aceptadas en la legislación para cubrir la totalidad del monto que se debe garantizar como cierre de minas.

No obstante, de acuerdo a lo planteado, en cualquier caso, la inversión forestal en garantía del cierre de minas no podrá ser inferior a un monto equivalente a tres millones de dólares. 
En segundo lugar, se establecen condiciones personales para que el titular minero pueda optar a garantizar su cierre de minas mediante un fideicomiso de inversión forestal. Así, los titulares mineros deberán tener calificados sus instrumentos financieros con grado igual o superior al equivalente a BBB por las Clasificadoras de Riesgos 0 , en caso los titulares no emitan instrumentos financieros, deberán demostrar que sus indicadores financieros de liquidez, rentabilidad y solvencia de los tres años previos a la presentación del Plan de Cierre de Minas se encuentran iguales o mejores que el promedio de los indicadores de las empresas mineras que reportan sus estados financieros a la Superintendencia del Mercado de Valores (antes Comisión Nacional Supervisora de Empresas y Valores - CONASEV).

Finalmente, se indica que en cualquiera de los dos casos señalados en el párrafo anterior, se deberá demostrar que las actividades mineras se realizan bajo buenas prácticas ambientales y sociales.

\section{Crítica a la regulación del fideicomiso de inversión forestal como garantía del cierre de minas}

A pesar que el fideicomiso de inversión forestal se incluyó como una de las modalidades de garantía de cierre de minas hace casi diez años, hasta la fecha no ha sido utilizado por ningún titular minero. Esto se debe a la poca difusión del mecanismo $y$, principalmente, a las desventajas que tiene su acceso frente a otras modalidades de garantía de cierre mucho más expeditivas para el inversionista.

En efecto, mientras que para garantizar el cierre de minas mediante, por ejemplo, una carta fianza, únicamente es necesario indicar en el Plan de Cierre de Minas que se utilizará este mecanismo. Por otro lado, de querer optar por un fideicomiso de inversión forestal, se deberá presentar el proyecto del contrato de fideicomiso, el proyecto y estudio de factibilidad, y los documentos que acrediten el acceso al terreno que recibirá la inversión, conjuntamente con el Plan de Cierre de Minas. Esto, sin perjuicio de que adicionalmente se debe señalar que por lo menos el $50 \%$ restante del monto del cierre de minas se garantizará mediante otra modalidad de garantía.

Incluso, ya habiéndose aprobado el Plan de Cierre de Minas contemplando el uso del fideicomiso de inversión forestal, no existe una disposición expresa que impida que el Ministerio de Energía y Minas pueda rechazar su constitución a efectos de garantizar el cierre. Es decir, el titular minero se verá obligado a elaborar el proyecto de inversión y el estudio de factibilidad, para obtener el acceso al terreno superficial (todo lo cual tiene un costo), e incluso para obtener la aprobación de esta inversión en el Plan de Cierre de Minas, sin tener la predictibilidad de que la autoridad aceptará la constitución del fideicomiso como garantía.

De esta forma, mientras que para hacer uso de una carta fianza únicamente se deberá solicitar a la entidad financiera autorizada su emisión, y asumir el costo por su emisión y mantenimiento, para el fideicomiso se estará sujeto al cumplimiento de diversas 
condiciones para tener por garantizado el cierre de minas y poder realizar las actividades mineras, sin tener una razonable certeza de su aceptación por la autoridad.

Lo anterior desincentiva a los inversionistas mineros pues los expone a un riesgo ajeno al que conocen y controlan como parte de su negocio, que es la actividad minera y no la actividad forestal. De esta forma, resulta difícil que un empresario minero decida asumir el riesgo de un sector que no conoce y que, de tener un resultado negativo, podría impedir el desarrollo de su negocio principal. Ello teniendo en consideración, además, la nula experiencia del Ministerio de Energía y Minas evaluando proyectos de inversión forestal como garantía del cierre de minas.

Este desincentivo se ve incrementado por el hecho de que optar por un fideicomiso de inversión forestal no le genera ningún beneficio al titular minero, sino que, por el contrario, ocasiona mayores exigencias y controles financieros. Sobre el particular, nótese que para ser titular minero no se requiere contarcon algún grado de inversión de Clasificadoras de Riesgo o un estado financiero superior al promedio de los indicadores de la Superintendencia del Mercado de Valores, condiciones que sí se requieren para optar por garantizar el cierre mediante un fideicomiso de inversión forestal.

En suma, el fideicomiso de inversión forestal, como está concebido actualmente, no genera ningún incentivo para ser utilizado por los titulares mineros, más allá que desde un punto de vista ambiental para la sociedad, y de reputación para la empresa, sea favorable.

Indudablemente no se trata de flexibilizar el acceso al fideicomiso de inversión forestal como garantía del cierre de minas de forma tal que ésta misma obligación pueda verse socavada. Sin embargo, sí resulta necesario que el Estado, a través del Ministerio de Energía y Minas, reevalúe e implemente una regulación que efectivamente incentive que los titulares mineros garanticen el cierre de minas mediante el fideicomiso de inversión forestal, conforme a la declaración de interés nacional que tiene la promoción de la inversión privada en actividades de reforestación con plantaciones forestales, agroforestería y servicios ambientales realizada por la Ley 28852.

A este efecto, algunos de los puntos que deben ser considerados para mejorar la regulación actual sobre el uso del fideicomiso de inversión forestal como garantía del cierre de minas son los siguientes:

No imponer un porcentaje máximo del monto de cierre de minas que pueda ser garantizado mediante el fideicomiso de inversión forestal. De esta forma los titulares mineros, de querer utilizar este mecanismo, no se verán obligados también a utilizar otra modalidad de garantía. 
- No imponer un monto mínimo de inversión inicial valorizada. Esto permitirá que cualquier titular minero (sin importar la envergadura de su proyecto o unidad minera) pueda constituir un fideicomiso en garantía del cierre de minas.

- Eliminar la obligación de demostrar que las actividades mineras se realizan bajo buenas prácticas ambientales y sociales. Por un lado, el cumplimiento de las obligaciones de protección ambiental es imperativo, sin que exista la posibilidad de que algún titular minero se exonere de su cumplimiento (salvo por los supuestos previstos en las mismas normas) bajo riesgo de ser sancionado por la autoridad competente. Por otro lado, las buenas prácticas ambientales y sociales (entendidas como un estándar mayor al impuesto legalmente) son figuras que deben ser también fomentadas mediante otros incentivos, no debiendo ser utilizadas para evitar el acceso a otra actividad de interés nacional como lo es el desarrollo forestal.

- Permitir la asociación entre titulares mineros a fin de constituir fideicomisos de inversión forestal a fin de garantizar sus respectivos cierres de mina, de acuerdo a la participación que le corresponda a cada uno.

- Implementar reglas que otorguen predictibilidad al inversionista, de tal forma que exista la certeza que habiéndose aprobado el proyecto de contrato de fideicomiso y el estudio de factibilidad con el Plan de Cierre de Minas, la constitución de la garantía será aceptada por la autoridad. Es decir, eliminar el riesgo de que habiendo realizado la inversión para el desarrollo de la factibilidad del proyecto de inversión forestal, este proyecto pueda ser rechazado por el Ministerio de Energía y Minas. 